Slavica

bruxellensia

\section{Slavica bruxellensia}

Revue polyphonique de littérature, culture et histoire

slaves

$8 \mid 2012$

Migration(s) et Exil(s)

\title{
Jelle Brandt Corstius, Rusland voor gevorderden
}

\section{Bas Van der Ham}

\section{OpenEdition \\ Journals}

Édition électronique

URL : http://journals.openedition.org/slavica/1197

DOI : 10.4000/slavica. 1197

ISSN : 2034-6395

Éditeur

Université libre de Bruxelles - ULB

Référence électronique

Bas Van der Ham, « Jelle Brandt Corstius, Rusland voor gevorderden », Slavica bruxellensia [En ligne], 8 2012, mis en ligne le 26 juin 2012, consulté le 22 septembre 2020. URL : http://

journals.openedition.org/slavica/1197; DOI : https://doi.org/10.4000/slavica.1197

Ce document a été généré automatiquement le 22 septembre 2020.

\section{(c) (i) () $\Theta$}

Les contenus de Slavica bruxellensia sont mis à disposition selon les termes de la Licence Creative Commons Attribution - Pas d'Utilisation Commerciale - Pas de Modification 3.0 France. 


\title{
Jelle Brandt Corstius, Rusland voor gevorderden
}

\author{
Bas Van der Ham
}

RÉFÉRENCE

Corstius J. B., Rusland voor gevorderden, Amsterdam, Prometheus, 2008, 187 p. 
1 La liberté de la presse en Russie et dans les anciennes républiques soviétiques a déjà fait couler beaucoup d'encre. On le sait, les journalistes russes se trouvent dans des situations pénibles et éprouvent de grandes difficultés à publier leurs articles critiques. Les correspondants étrangers qui se trouvent sur place font le même travail et écrivent eux aussi des articles qui ne sont pas du goût du gouvernement. En tant qu'étrangers, ontils moins de difficultés que leurs collègues locaux ? Comment s'organisent-ils et où se situe la limite de la tolérance du régime? Jusqu'où sont-ils prêts à aller au nom de la liberté ?

Dans son livre Russland voor gevorderden (La Russie pour les initiés),Jelle Brandt Corstius se met dans la peau d'un journaliste hollandais en Russie et dans les régions adjacentes. Il s'agit d'un rapport personnel qui donne une image surprenante des possibilités et impossibilités journalistiques en Russie.

3 L'histoire qui se profile derrière celles, personnelles, des gens qu'on voit et qu'on lit dans les médias est décrite d'une manière très positive, humaine et honnête. L'auteur parvient même à voir le côté ludique des confrontations avec la bureaucratie, le côté surréaliste de ce pays, les procédures pour l'obtention des visas et les multiples problèmes avec les propriétaires d'appartements. Il évoque aussi les grands thèmes de l'actualité en portant une grande attention sur les gens ordinaires, les messieurs Toutle-monde, en essayant d'expliquer comment ils se sont retrouvés dans de telles situations. Nous obtenons ainsi un point de vue tout à fait nouveau et surprenant sur l'actualité russe qui devient une initiation à la culture russe. Car le but du livre est d'en expliquer les aspects insaisissables a priori.

Brandt Corstius semble être à la fois méticuleux et honnête, et il n'a pas peur de témoigner de certains aspects négatifs de la Russie, comme les médias russes qui ne donnent pas vraiment d'espoir, et ce, pas seulement à cause du gouvernement :

La soirée s'est conclue sur un long discours du ministre dans lequel il a remercié tous les journalistes. Il a répété qu'ils n'avait pas pu parler avec l'opposition. Désolé, ces « journalistes » étaient bien trop occupés par le sauna et le buffet de l'hôtel cinq étoiles. (...) Puis le ministre a payé l'addition pour toute cette clique. En ce qui concerne le journalisme, la situaton est encore plus triste que durant les années de soviétisme. (p. 44)

Malgré cela, on ne sent pas cette amertume que l'on trouve par exemple dans les derniers livres d'Anna Politkovskaïa. Brandt Corstius aime la Russie et ne ferme pas les yeux sur son côté noir.

5 Par ailleurs, il s'agit d'un auteur qui lutte pour la liberté d'expression, surtout dans le cadre de ses reportages. On se souviendra de celui sur les déserteurs de l'armée russe ; 
il avait alors subi des pressions : ses contacts avaient été intimidés par les services secrets, son matériel vidéo saboté. Les articles et reportages qu'il réalisa par la suite se teintèrent petit à petit d'amertume. Malheureusement, les thèmes qu'il se mit à traiter furent plus stéréotypés, plus proches des histoires qu'on lit partout sur la Russie : problèmes avec l'environnement, répression, alcoolisme, terrorisme, racisme, etc., probablement sous la pression des médias de plus en plus sensationnels. Il finit par renoncer à son aventure russe et retourna aux Pays-Bas.

6 Malgré tout, Russalnd voor gevorderden sape beaucoup de stéréotypes sur la Russie et pourrait même enthousiasmer les gens qui ne s'intéressent pas à ce pays immense.

\section{INDEX}

Index géographique : Russie

Index chronologique : communisme, époque contemporaine, XXe siècle, XXIe siècle

Mots-clés : histoire de la Russie

\section{AUTEURS}

\section{BAS VAN DER HAM}

Étudiant en slavistique à l'Université Libre de Bruxelles 